\title{
High Herpesvirus Diversity in Wild Rodent and Shrew Species in Central Africa
}

\author{
Nkom Felix Ntumvi ${ }^{a} \quad$ Placide Mbala Kingebeni ${ }^{a} \quad$ Ubald Tamoufe ${ }^{a}$ \\ Charles Kumakamba $^{a}$ Valentine Ndze ${ }^{a}$ Ipos Ngay Lukusa ${ }^{a}$ \\ Matthew LeBreton ${ }^{b}$ Joseph Atibu Losoma ${ }^{c}$ Joseph Le Doux Diffo ${ }^{a}$ \\ Frida N'Kawa $^{\mathrm{a}}$ Jean-Michel Takuo ${ }^{\mathrm{a}}$ Prime Mulembakani $^{\mathrm{a}}$ \\ Julius Nwobegahay ${ }^{d}$ Maria Makuwa ${ }^{\text {a }}$ Jean J. Muyembe Tamfum ${ }^{\mathrm{e}}$ \\ Amethyst Gillis $^{\text {a }}$ Stephen Harris ${ }^{a}$ Anne W. Rimoin ${ }^{f}$ Nicole A. Hoff ${ }^{f}$ \\ Joseph M. Fair a, h Corina Monagin a, ${ }^{\text {g }}$ James Ayukekbong ${ }^{a}$ Edward M. Rubin ${ }^{a}$ \\ Nathan D. Wolfe ${ }^{a}$ Christian E. Lange ${ }^{a}$

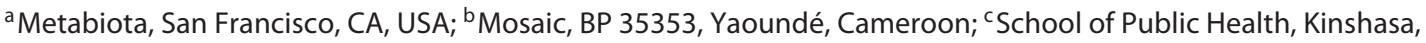

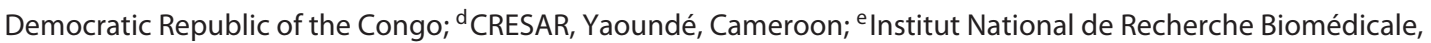

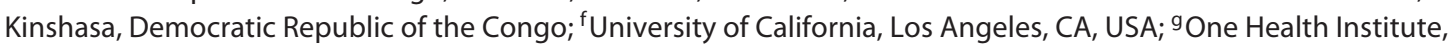 \\ School of Veterinary Medicine, University of California, Davis, CA, USA; hVIRION, New Orleans, LA, USA
}

\section{Keywords}

Herpesvirus · PCR · Diversity · Rodent · Shrew · Central Africa

\begin{abstract}
Objective: Herpesviruses belong to a diverse order of large DNA viruses that can cause diseases in humans and animals. With the goal of gathering information about the distribution and diversity of herpesviruses in wild rodent and shrew species in central Africa, animals in Cameroon and the Democratic Republic of the Congo were sampled and tested by PCR for the presence of herpesvirus DNA. Methods: A broad range $P C R s$ targeting either the Polymerase or the terminase gene were used for virus detection. Amplified products from
\end{abstract}

PCR were sequenced and isolates analysed for phylogenetic placement. Results: Overall, samples of 1,004 animals of various rodent and shrew species were tested and 24 were found to be positive for herpesvirus DNA. Six of these samples contained strains of known viruses, while the other positive samples revealed DNA sequences putatively belonging to 11 previously undescribed herpesviruses. The new isolates are beta- and gammaherpesviruses and the shrew isolates appear to form a separate cluster within the Betaherpesvirinae subfamily. Conclusion: The diversity of viruses detected is higher than in similar studies in Europe and Asia. The high diversity of rodent and shrew species occurring in central Africa may be the reason for a higher diversity in herpesviruses in this area.

(c) 2018 S. Karger AG, Basel

\section{KARGER}

(c) 2018 S. Karger AG, Basel

E-Mail karger@karger.com

www.karger.com/int
Christian E. Lange

Metabiota

7-1611 Bowen Road

Nanaimo, BC V9S 1 G5 (Canada)

E-Mail clange_virology@gmx.de 


\section{Introduction}

Herpesviruses are large DNA viruses that can cause diseases in humans and animals and have a global distribution. While most currently known herpesviruses belong into the family Herpesviridae and infect mammals, birds, and reptiles, their cousins in the families Allherpesviridae, infecting fish and frogs, and Malacoherpesviridae, infecting bivalves, highlight the evolutionary age and incredible diversity within the Herpesvirales order [1-3]. The large Herpesviridae family itself has 3 subfamilies, the Alpha-, Beta-, and Gammaherpesvirinae that significantly differ in their DNA sequences, genome organisation, immunologic relationship, and biology. Below the subfamily level, herpesviruses are classified into Genera, Species, and variants based on their DNA sequence, biological characteristics, and the ecological niche they occupy $[3,4]$.

Herpesviruses usually establish lifelong latent infections that are free of clinical symptoms, while reactivation can happen at any time [4]. Herpesviruses are largely host specific and have to a large part co-evolved with their host species. However, cross-species transmission has probably occurred in the past and contributed to the herpesvirus evolution [5]. Several examples of presently circulating herpesvirus species underline this capacity to crossover into related host species, such as Ovine herpesvirus 2 (OvHV-2) and the Alcelaphine herpesvirus 1 (AlHV-1), which both do not induce clinical symptoms in their reservoir hosts, but cause malignant catarrhal fever in cattle and other ungulates [6]. Similarly, there is zoonotic $\mathrm{Ma}$ cacine herpesvirus 1 (McHV-1), also known as herpes $\mathrm{B}$ virus, a species of monkey virus that can cause severe disease in humans [7].

While an increasing number of studies suggest that most animal species harbour their own set of herpesviruses, those of rodents in particular have become a focus in recent years $[1,4,5]$. This is less out of concerns about zoonotic potential but more so because they might provide a practical model for the herpesvirus biology and pathology of human herpesviruses [8-10]. Some rodent herpesvirus species, such as Murid herpesviruses 1, 2, and 4 , have been studied in some detail, but considering the global diversity of rodent and shrew species it can be assumed that many more herpesvirus species might exist. Previous studies on their diversity focussed on animals sampled in Europe and Asia and indicate that such viruses indeed might be plentiful and diverse $[11,12]$. The goal of the present study was to get a better view of the genetic diversity of herpesviruses in wild rodent and shrew species in central Africa. It was undertaken as part of the global USAID-funded Emerging Pandemic Threats (EPT) PREDICT project that aims to enhance global capacity for the detection and discovery of viruses at the human-animal interface.

\section{Materials and Methods}

Samples from rodents and shrews were collected opportunistically between January 2009 and June 2013 in several locations in Cameroon (CMR) and the Democratic Republic of the Congo (DRC; Fig. 1). Specimen collection from these wild animals was approved by the Institutional Animal Care and Use Committee (IACUC, UC Davis) and the governments of CMR and DRC. People who reported hunting or butchering wild animals in rural areas volunteered to collect blood samples from animals they had hunted. They were collected as dried blood samples (DBS) on Whatman paper during butchering and allowed to air dry before storage in labelled envelopes. All DBS samples were stored in clip lock plastic bags with silica gel at room temperature until further processing. Whole blood and necropsy samples were obtained in villages and in bushmeat markets in CMR, and were placed in cryotubes and frozen in liquid nitrogen. In DRC, tissue samples were collected in RNA-later (Qiagen) from captured animals and kept at room temperature. The samples were initially stored at $-20^{\circ} \mathrm{C}$ and later transferred to $-80^{\circ} \mathrm{C}$ or directly stored at $-80^{\circ} \mathrm{C}$ until further processing.

Samples were subjected to DNA extraction using the Qiagen Allprep DNA/RNA kit (tissue samples) or Qiagen QIAamp DNA Mini kit (DBS samples) according to the manufacturer's instructions. The DNA was stored at $-20^{\circ} \mathrm{C}$ until analysis. Two different nested PCR assays were used with the choice of preferred test being up to the local laboratory. One of the PCRs targets was the conserved DNA packaging terminase subunit 1 gene (Ter) and produces a sequence fragment of approximately $374 \mathrm{nt}$ flanked by the primer sequences [13]. The primers for the first round (TSTERM_707s and TS-TERM_707as) as well as for the second round (TS-TERM_708s and TS-TERM_708as) of the PCR are degenerated to enable the detection of a variety of herpesviruses ( $\mathrm{Ta}$ ble 1). The other PCR targets the conserved catalytic subunit of the DNA polymerase catalytic subunit gene (DPOL) and produces a sequence fragment of approximately $175 \mathrm{nt}$ flanked by the primer sequences [14]. For this PCR assay the primers for the first round (ILK and KG1) and the second round (TGV and IYG) are also degenerated to enable the detection of a variety of herpesviruses (Table 1). Samples from CMR were tested for the presence of herpesvirus DNA using a nested broad range PCR targeting the terminase gene (Ter) [13]. Samples collected in the DRC were first tested with a nested broad range PCR targeting DPOL [14]. Putative positive samples in the DRC were additionally tested with the Ter PCR.

The samples positive for viral DNA were additionally tested with a Cytochrome b PCR assay to confirm the host species wherever the morphological identification was not possible to the species level [15]. The primers CytB_F and CytB_R were used to amplify a 435-nt fragment of the highly conserved mitochondrial gene, which is flanked by the primer binding sites (Table 1). 
Fig. 1. Map of the sampling sites in CMR and the DRC. Pie charts indicating the rough magnitude of samples taken in 1 location with yellow representing rodent and blue indicating shrew species proportionally. Sites without shrew sampling are displayed in yellow with a black line at 12 o'clock. Sampling sites within $25 \mathrm{~km}$ of each other are presented as one.

Table 1. PCR primer

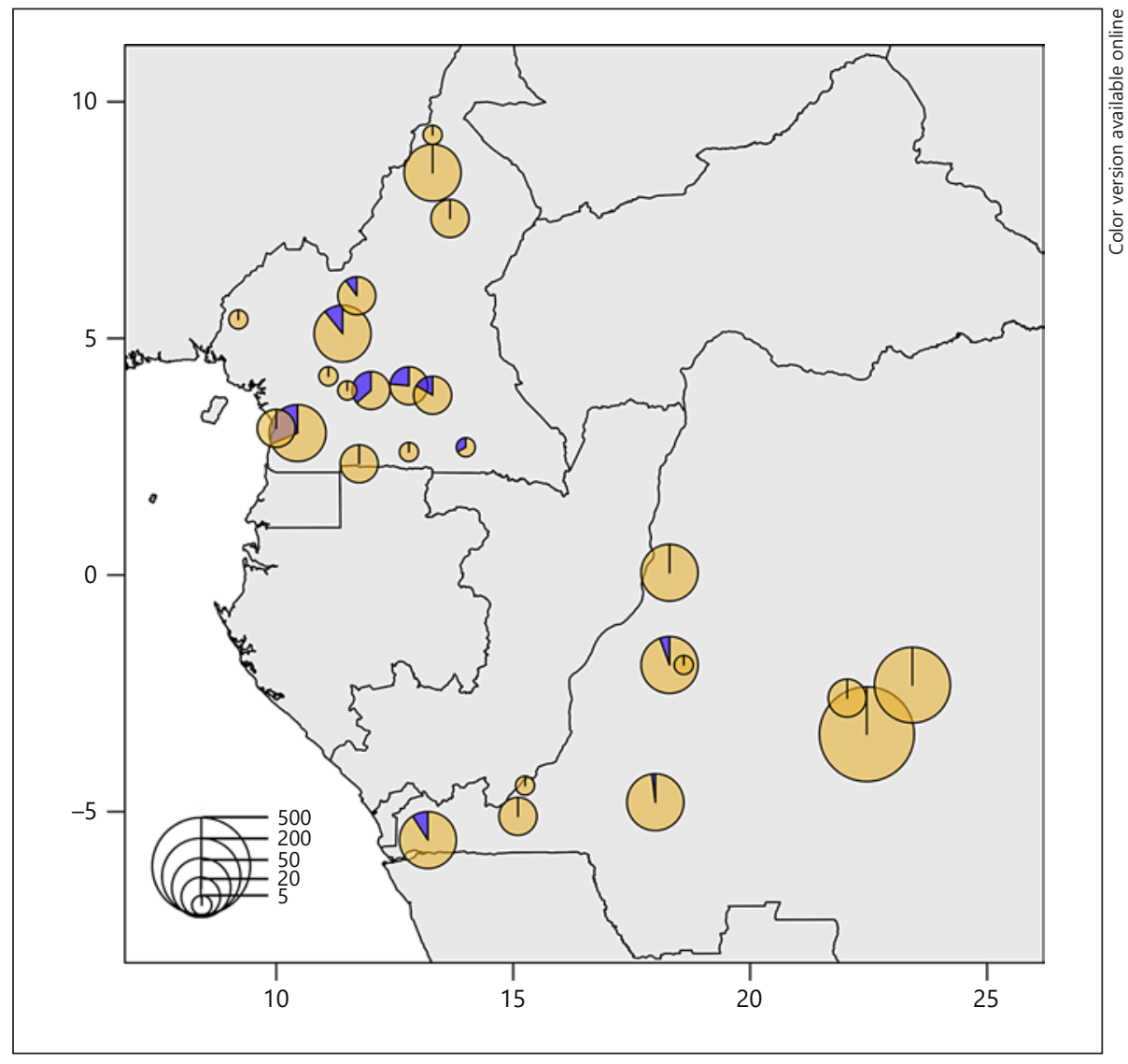

\begin{tabular}{ll}
\hline Primer & Sequence \\
\hline TS-TERM_707s & TTG TGG ACG AGR SIM AYT TYA T \\
TS-TERM_707as & ACA GCC ACG CCN GTI CCI GAI GC \\
TS-TERM_708s & GCA AGA TCA TNT TYR TNT CNT C \\
TS-TERM_708as & TGT TGG TCG TRW ANG CNG GRT \\
ILK & TCC TGG ACA AGC AGC ARN YSG CNM TNA A \\
KG1 & GTC TTG CTC ACC AGN TCN CAN CCY TT \\
TGV & TGT AAC TCG GTG TAY GGN TTY CAN GGN GT \\
IYG & CAC AGA GTC CGT RTC NCC RTA DAT \\
CytB_F & GAG GMC AAA TAT CAT TCT GAG G \\
CytB_R & TAG GGC VAG GAC TCC TCC TAG T \\
\hline
\end{tabular}

All PCR products were run on a 1.5\% agarose gel and the corresponding size fragments excised. DNA was extracted using either the Qiagen QIAquick Gel Extraction Kit or the Promega Wizard SV Gel and PCR Clean-Up System and were sent for commercial sanger sequencing at GATC Biotech (Germany). The sequencing results were assessed and processed using Geneious 7.1.

A phylogenetic tree based on the PCR target region in Ter consisting of 50 published herpesviruses sequences and the isolates detected here was constructed. The published sequences were selected to represent all genera within the Alpha-, Beta-, and Gammaherpesvirinae subfamilies with at least 2 members (if sequence available) as well as all known rodent- and shrew-specific herpesvirus species. For that purpose, multiple sequence alignments were made in Geneious (version 9.1.8, ClustalW Alignment), and regions where more than $50 \%$ of the sequences had gaps were removed. The optimal model of DNA evolution was evaluated for best fit of the dataset using MODELTEST (version 1.4.4) using the default settings. Bayesian phylogeny of the Ter set was inferred using MRBAYES (version 3.2); Markov Chain Monte Carlo with GTR substitution matrix, variable gamma rates, invariant sites, 2 runs, 4 chains of 15,000,000 generations. Acipenserid herpesvirus 2 (AciHV-2) served as an outgroup to root the trees and trees were 
Table 2. Herpes DNA-positive samples

\begin{tabular}{|c|c|c|c|c|}
\hline $\begin{array}{l}\text { Sampling } \\
\text { location }\end{array}$ & Species (host) ${ }^{\mathrm{a}}$ & $\begin{array}{l}\text { Sample type } \\
\text { and PCR }\end{array}$ & $\begin{array}{l}\text { BLAST N } 11 / 25 / 16^{\mathrm{b}} \text { and likely } \\
\text { subfamily }\end{array}$ & $\begin{array}{l}\text { Isolate name and } \\
\text { GenBank ID }\end{array}$ \\
\hline $\begin{array}{l}\text { DRC, } \\
\text { Sankuru }\end{array}$ & $\begin{array}{l}\text { Rodentia, Sciuridae, } \\
\text { Funisciurus spp }\end{array}$ & $\begin{array}{l}\text { Blood } \\
\text { terminase }\end{array}$ & $\begin{array}{l}\text { Murid herpesvirus } 1 \text { (HE610455), } \\
81 \% \text { ident (99\% cover) } \\
\text { Beta HV }\end{array}$ & $\begin{array}{l}\text { Rodent HV DRC } 1 \\
\text { KY398043 }\end{array}$ \\
\hline $\begin{array}{l}\text { DRC, } \\
\text { Sankuru }\end{array}$ & $\begin{array}{l}\text { Rodentia, Sciuridae, } \\
\text { Funisciurus pyrropus }\end{array}$ & $\begin{array}{l}\text { Blood } \\
\text { terminase }\end{array}$ & $\begin{array}{l}\text { Murid herpesvirus } 1 \text { (HE610455), } \\
81 \% \text { ident (99\% cover) } \\
\text { Beta HV }\end{array}$ & $\begin{array}{l}\text { Rodent HV DRC } 1 \\
\text { KY398043 }\end{array}$ \\
\hline $\begin{array}{l}\text { DRC, } \\
\text { Sankuru }\end{array}$ & $\begin{array}{l}\text { Rodentia, Muridae, } \\
\text { Rattus rattus }\end{array}$ & $\begin{array}{l}\text { Blood } \\
\text { DPOL }\end{array}$ & $\begin{array}{l}\text { Bandicota indica rhadinovirus } 1 \\
\text { (EF128040), 99\% ident (100\% cover) } \\
\text { Beta HV }\end{array}$ & $\mathrm{NA}^{\mathrm{c}}$ \\
\hline $\begin{array}{l}\text { DRC, } \\
\text { Sankuru }\end{array}$ & $\begin{array}{l}\text { Rodentia, Muridae, } \\
\text { Cricetomys spp }\end{array}$ & $\begin{array}{l}\text { Blood } \\
\text { DPOL }\end{array}$ & $\begin{array}{l}\text { Sorex araneus betaherpesvirus } 1 \\
\text { (JF705866), 77\% ident (62\% cover) } \\
\text { Beta } H V\end{array}$ & $\begin{array}{l}\text { Rodent HV DRC } 2 \\
\text { KY398049 }\end{array}$ \\
\hline $\begin{array}{l}\text { DRC, } \\
\text { Equateur }\end{array}$ & $\begin{array}{l}\text { Rodentia, Muridae, } \\
\text { Rattus rattus }\end{array}$ & $\begin{array}{l}\text { Liver/spleen } \\
\text { DPOL }\end{array}$ & $\begin{array}{l}\text { Rattus norvegicus rhadinovirus } 2 \\
\text { (EF128039), 99\% ident (100\% cover) } \\
\text { Beta HV }\end{array}$ & $\mathrm{NA}^{\mathrm{c}}$ \\
\hline $\begin{array}{l}\text { DRC, } \\
\text { Equateur }\end{array}$ & Rodentia, unidentified & $\begin{array}{l}\text { Liver/spleen } \\
\text { terminase }\end{array}$ & $\begin{array}{l}\text { Stealth virus } 1 \text { (U27238), } 74 \% \text { ident } \\
\text { (85\% cover) } \\
\text { Beta } \mathrm{HV}\end{array}$ & $\begin{array}{l}\text { Shrew HV CMR } 1 \\
\text { KY398040 }\end{array}$ \\
\hline $\begin{array}{l}\text { DRC, } \\
\text { Equateur }\end{array}$ & $\begin{array}{l}\text { Rodentia, Muridae, } \\
\text { Praomys spp }\end{array}$ & $\begin{array}{l}\text { Liver/spleen } \\
\text { DPOL }\end{array}$ & $\begin{array}{l}\text { Rattus norvegicus rhadinovirus } 2 \\
\text { (EF128039), 99\% ident (100\% cover) } \\
\text { Beta HV }\end{array}$ & $\mathrm{NA}^{\mathrm{c}}$ \\
\hline $\begin{array}{l}\text { DRC, } \\
\text { Kongo } \\
\text { Central }\end{array}$ & $\begin{array}{l}\text { Soricomorpha, Soricidae, } \\
\text { unidentified }\end{array}$ & $\begin{array}{l}\text { Liver/spleen } \\
\text { terminase }\end{array}$ & $\begin{array}{l}\text { Mandrillus leucophaeus } \\
\text { cytomegalovirus (KR297253), 74\% } \\
\text { ident ( } 85 \% \text { cover) } \\
\text { Beta } H V\end{array}$ & $\begin{array}{l}\text { Shrew HV DRC } 2 \\
\text { Shrew HV DRC } 3 \\
\text { KY398046/ } \\
\text { KY765894 }\end{array}$ \\
\hline $\begin{array}{l}\text { DRC, } \\
\text { Kwilu }\end{array}$ & $\begin{array}{l}\text { Rodentia, Muridae, } \\
\text { unidentified }\end{array}$ & $\begin{array}{l}\text { Liver/spleen } \\
\text { DPOL }\end{array}$ & $\begin{array}{l}\text { Mus musculus rhadinovirus } 1 \\
\text { (KP411252), 72\% ident ( } 74 \% \text { cover) } \\
\text { Gamma HV }\end{array}$ & $\begin{array}{l}\text { Rodent HV DRC } 3 \\
\text { KY398048 }\end{array}$ \\
\hline $\begin{array}{l}\text { DRC, } \\
\text { Kwilu }\end{array}$ & $\begin{array}{l}\text { Rodentia, Muridae, } \\
\text { unidentified }\end{array}$ & $\begin{array}{l}\text { Liver/spleen } \\
\text { DPOL }\end{array}$ & $\begin{array}{l}\text { Mus musculus rhadinovirus } 1 \\
\text { (KP411252), } 72 \% \text { ident ( } 74 \% \text { cover) } \\
\text { Gamma HV }\end{array}$ & $\begin{array}{l}\text { Rodent HV DRC } 3 \\
\text { KY398048 }\end{array}$ \\
\hline $\begin{array}{l}\text { CMR, } \\
\text { Centre }\end{array}$ & $\begin{array}{l}\text { Soricomorpha, Soricidae, } \\
\text { unidentified }\end{array}$ & $\begin{array}{l}\text { Liver/spleen } \\
\text { terminase }\end{array}$ & $\begin{array}{l}\text { Stealth virus } 1 \text { (U27238), 75\% ident } \\
\text { (86\% cover) } \\
\text { Beta } H V\end{array}$ & $\begin{array}{l}\text { Shrew HV CMR } 1 \\
\text { KY398040 }\end{array}$ \\
\hline
\end{tabular}


Table 2 (continued)

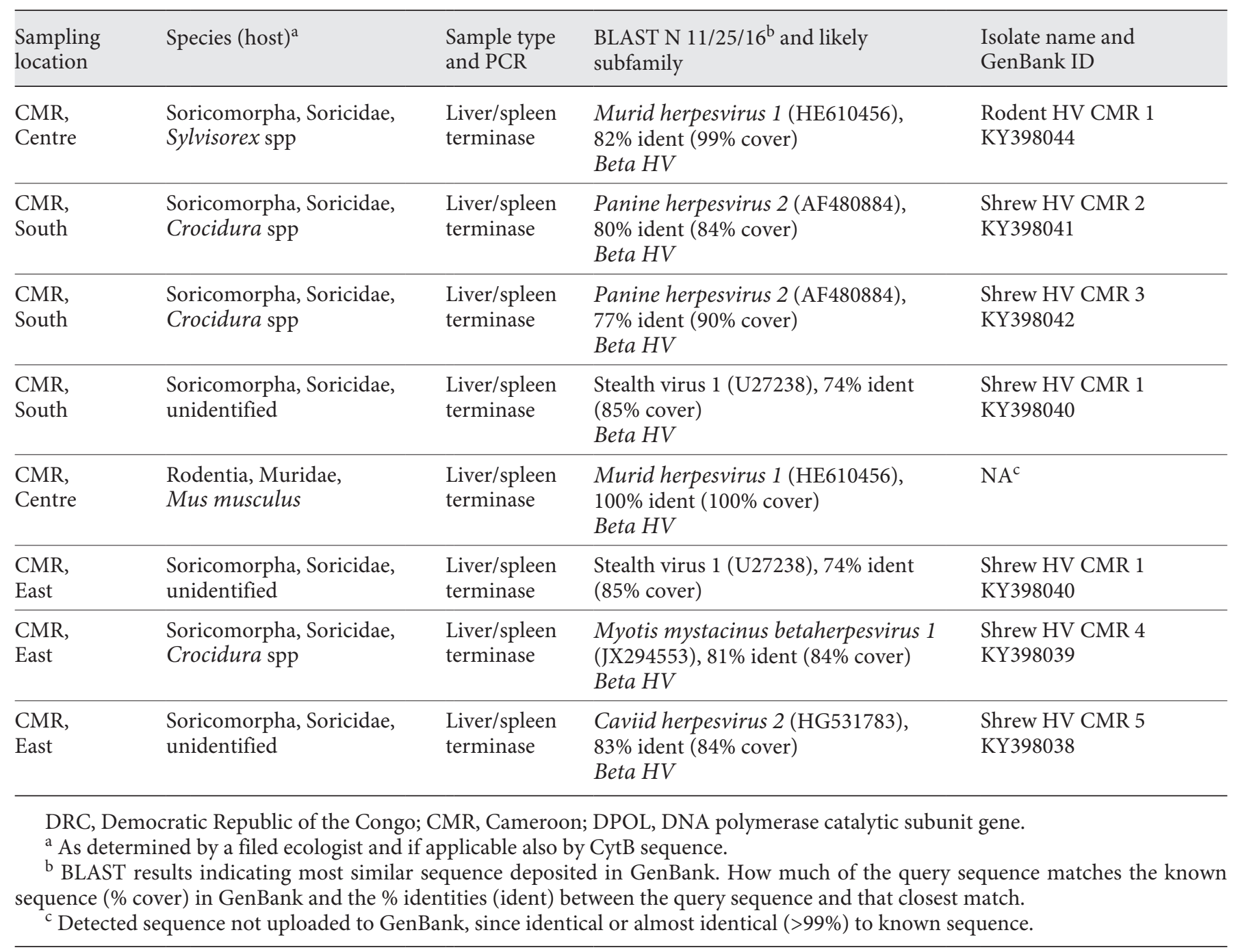

sampled after every 1,000 steps during the process to monitor phylogenetic convergence. The average standard deviation of split frequencies was below 0.0053 (Mr. Bayes recommended a final average $<0.01$ ). The first $10 \%$ of the trees were discarded and the remaining ones combined using TreeAnnotator (version 1.8.2; http://beast.bio.ed.ac.uk) and displayed with FIGTREE (1.4.2; http://tree.bio.ed.ac.uk/).

Sequences obtained from the Cytochrome b PCR were blasted against the GenBank database and assigned to species if the identity was $>97 \%$ compared to sequences available in Genebank.

\section{Results}

Overall samples from 1,004 rodents and shrews were collected, 785 in the DRC and 219 in CMR; for the vast majority, only 1 specimen was tested from each animal.
The sampling sites were predominantly in rural areas in various regions of CMR and in the western and central parts of the DRC (Fig. 1).

Of the samples tested, $96.8 \%$ were from rodents and $3.2 \%$ from shrews. Most of them had been hunted for consumption and the majority of samples (>99\%) were blood, liver, or spleen. Herpesvirus DNA was found in 24 animals $(2.4 \%)$, of which 14 were rodents and 10 were shrews (Table 2; Fig. 2). In CMR, $90 \%$ of the samples were tissue samples and viral DNA was only detected in tissue. In the DRC, $75 \%$ of the tested samples were DBS and $25 \%$ were tissue. Of the ones containing herpesvirus DNA, $33 \%$ were DBS and $67 \%$ were tissue. In 1 shrew 2 different herpesvirus sequence fragments were found in different tissues with the same PCR assay (Ter). Overall, the DPOL 


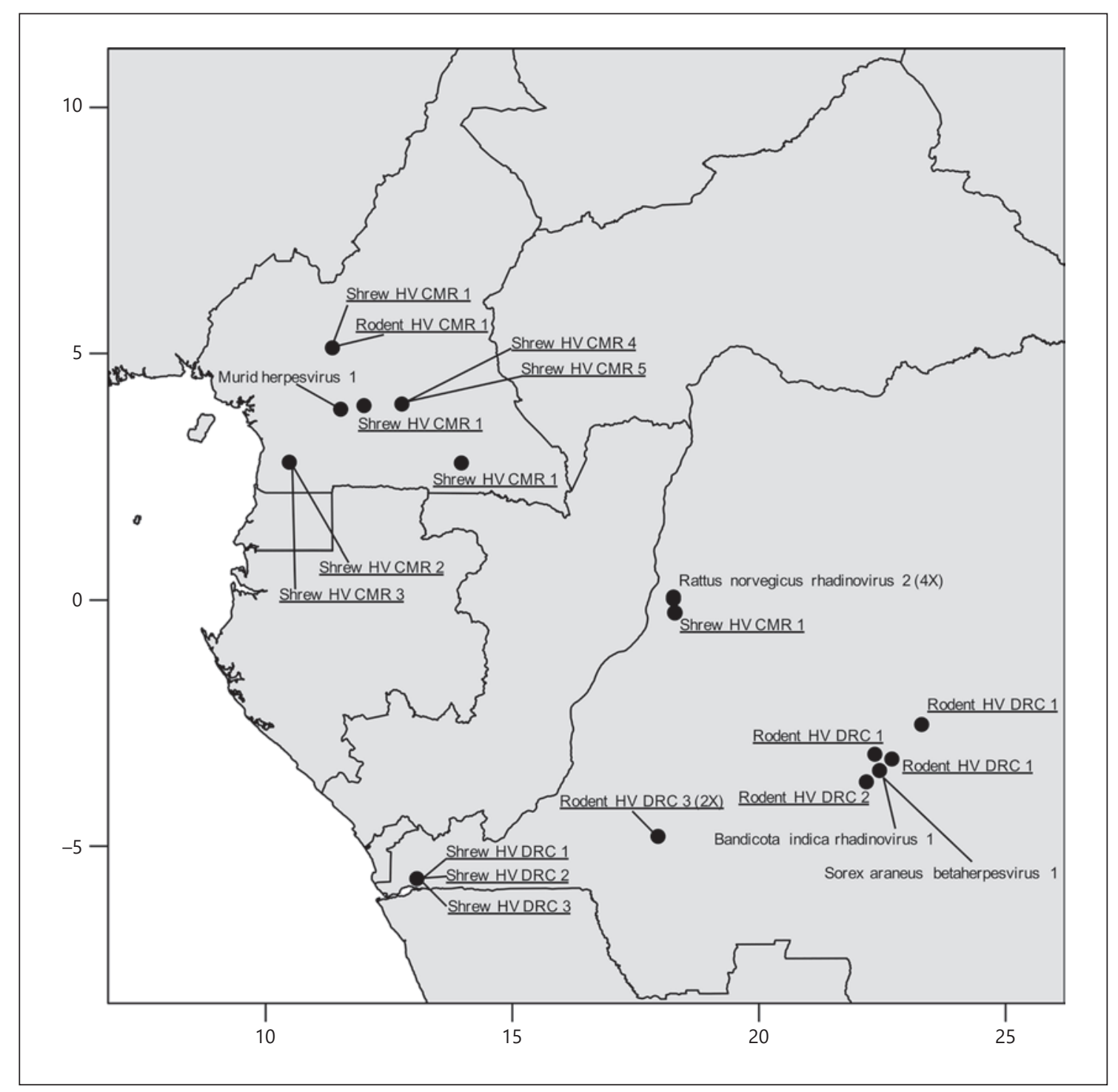

Fig. 2. Map of the sampling sites with herpesvirus-positive samples in CMR and the DRC. Sampling found 24 individuals that tested positive (1 with 2 different viruses), including 4 known viruses and 14 unique viruses. Unique (not previously reported) viruses are underlined on the map.

PCR produced 9 positive results (all from rodent samples) and the Ter PCR produced 16 (rodent and shrew samples; Table 2). All but 3 shrew samples were tested with Ter PCR. The sequences obtained fall into 2 groups. On the one side there are those that have a direct or very close match in GenBank, such as Murid herpesvirus 1, Rattus norvegicus rhadinovirus 2, and Bandicota indica rhadinovirus 1 . Six of the PCR positives fall into this category (Table 2). On the other side there are sequences that significantly $(>10 \%)$ differ from any published sequence. Nineteen of the obtained sequences fall into this category
(Table 2). Eleven of them are unique and also differ by more than $10 \%$ from each other; 1 differs by less the $4 \%$ and the other 7 by less than $1 \%$ from the unique sequences found here (Table 3a). Based on BLAST results, alignments, and on phylogenetic analysis, most of these novel sequences cluster with betaherpesvirus sequences, while 1 rodent isolate clusters with gammaherpesvirus sequences (Table 2, 3).

According to our alignments, the gammaherpesvirus sequence Rodent HV DRC 3 (KY398048) obtained with the DPOL PCR relates closest to Mus musculus rhadino- 
Table 3. Multiple sequence alignments

a Multiple sequence alignment based on Ter PCR fragment

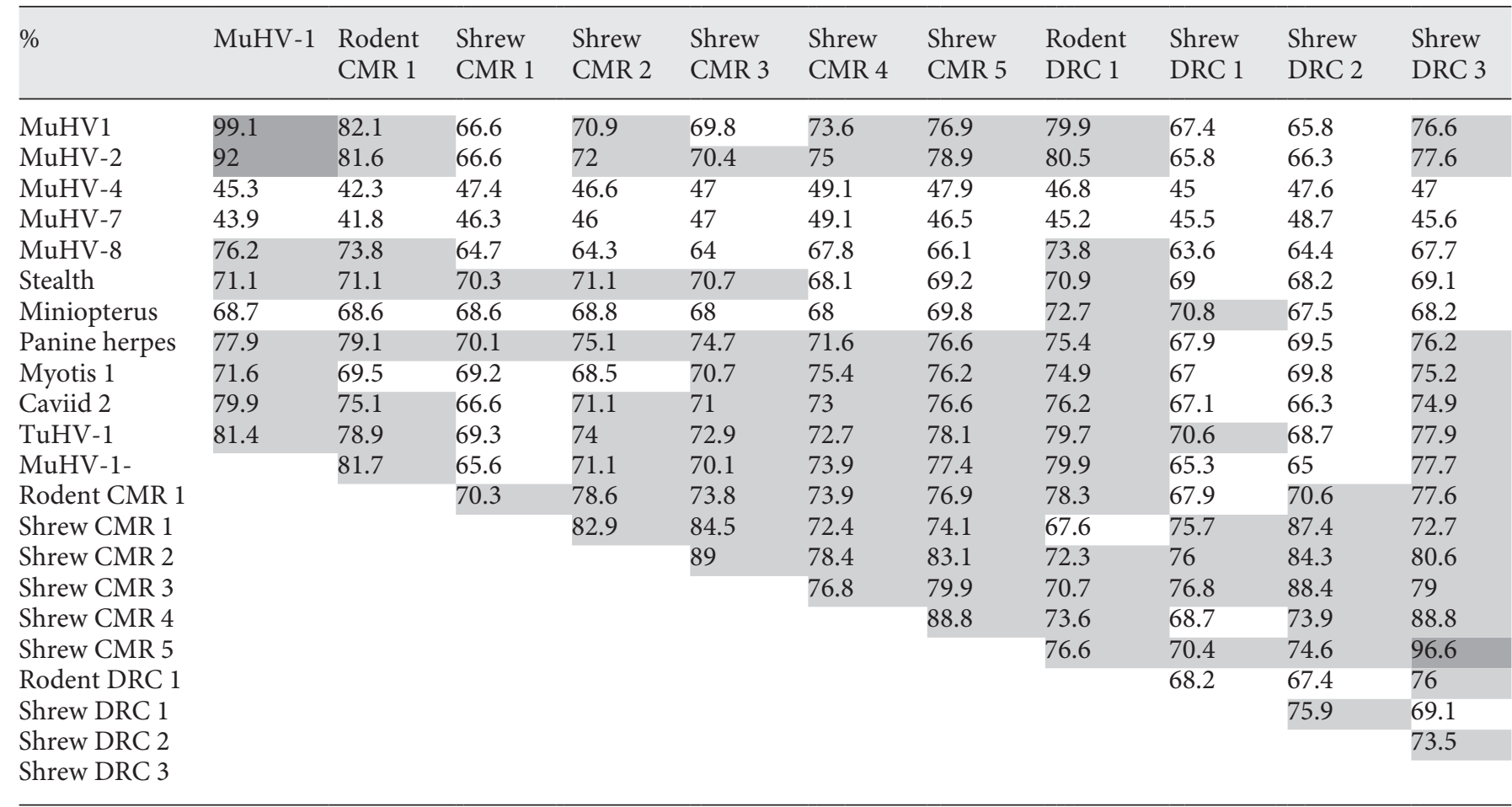

b Multiple sequence alignment based on DPOL PCR fragment

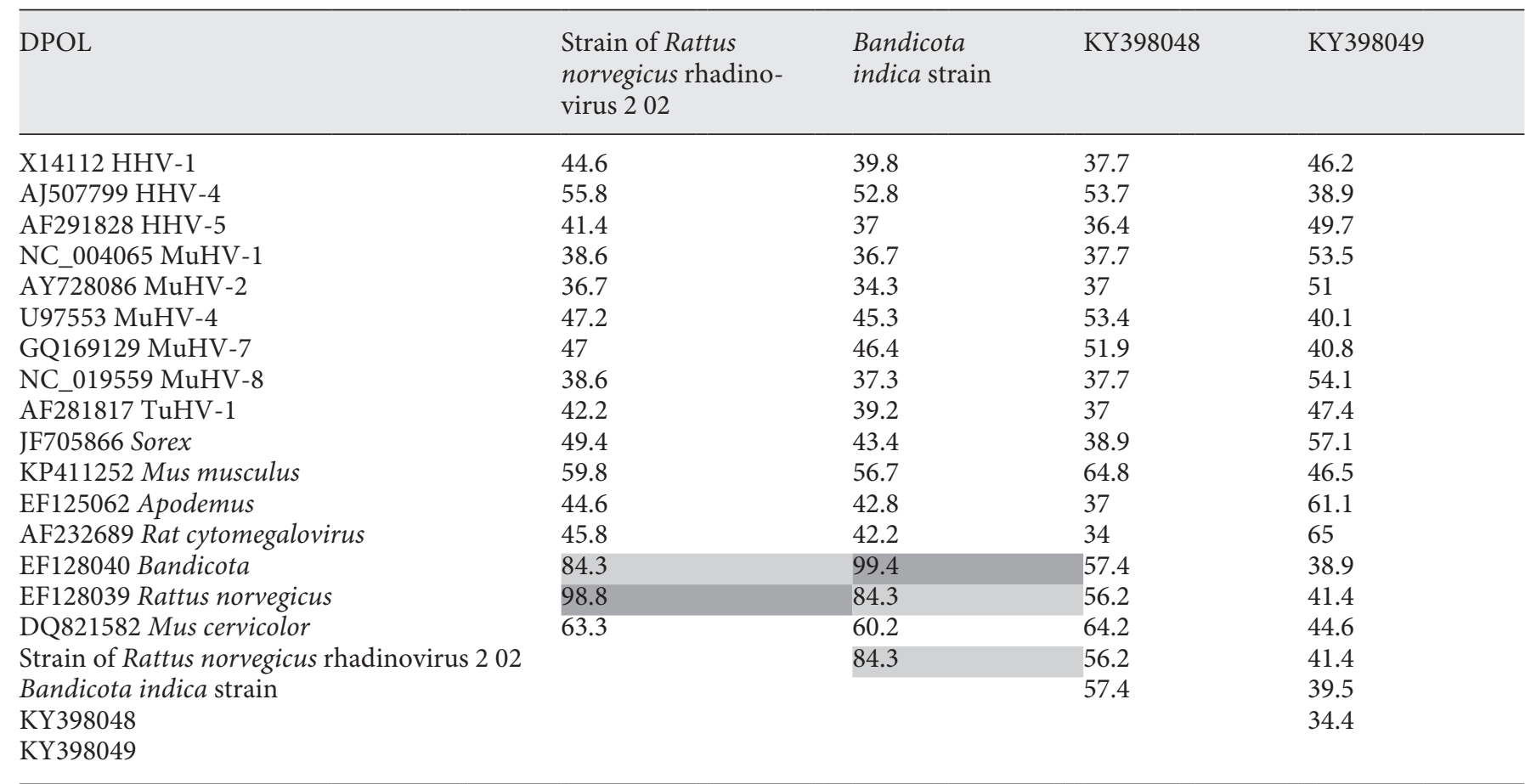

Dark/dense for $>90 \%$, light grey for $70-90 \%$, and none for $<70 \%$. 


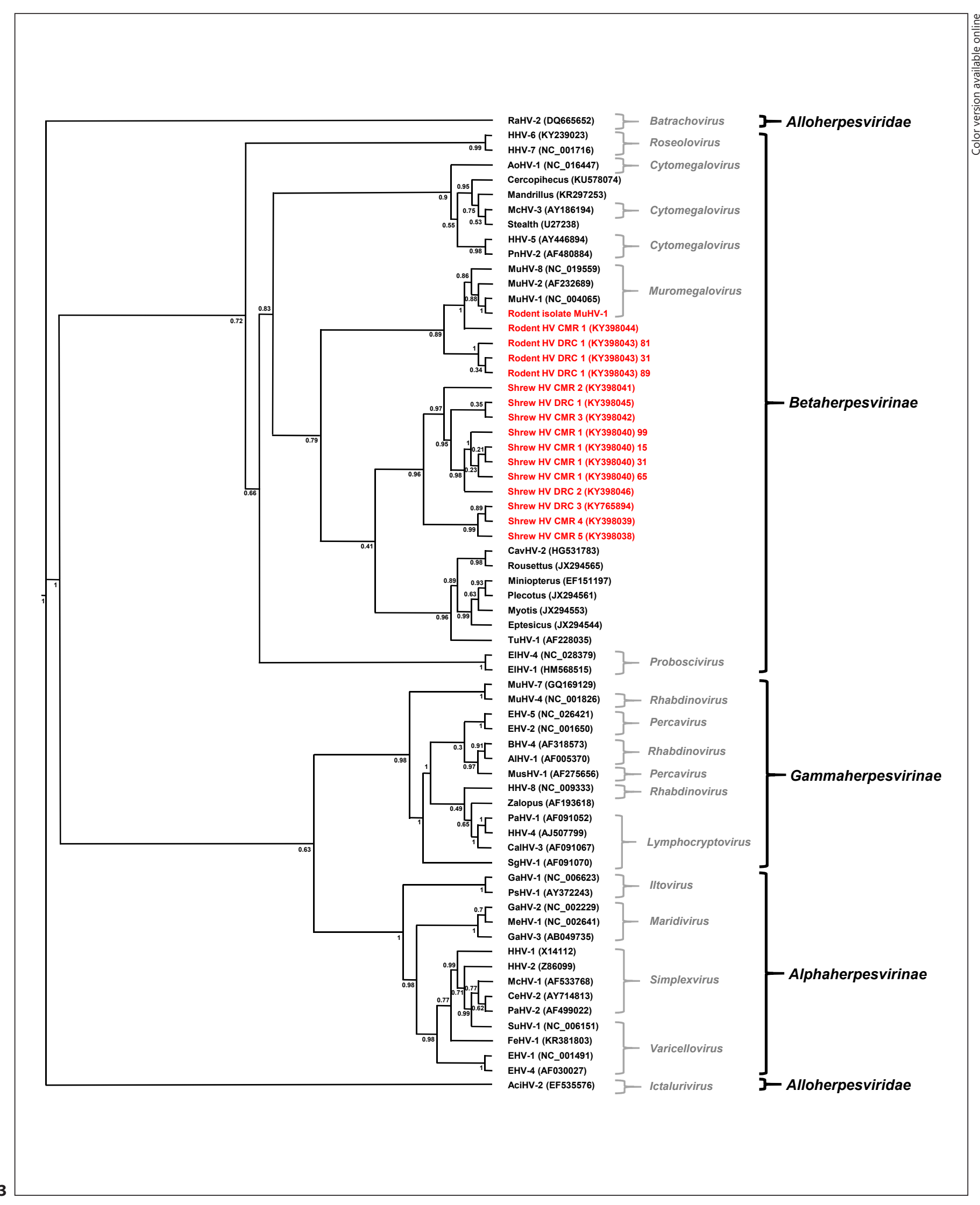

(For legend see next page.) 
virus 1 (KP411252) and Mus cervicolor rhadinovirus 1 (DQ821582), which were isolated from samples of mice in Afghanistan and Germany (Table 2,3b). The other new sequence, Rodent HV DRC 2 (KY398049) amplified by the DPOL PCR, aligns closest with Apodemus flavicollis cytomegalovirus 1 (EF125062) and Rat cytomegalovirus (AF232689), which were isolated from samples of mice and rats in Germany and the Netherlands (Tables 2, 3b).

The sequences obtained with the Ter PCR fall into 2 separate groups upon phylogenetic analysis (Fig. 3). Two of the new isolates align and cluster with Murid herpesvirus 1 (NC_004065), 2 (AF232689), and 8 (NC_019559). The other 8 new sequences, which were isolated from shrews, form their own distinct cluster among the betaherpesviruses (Fig. 3).

Of the sequences obtained from the Cytochrome $b$ PCR and blasted against the GenBank database, 6 had sequences which matched (>97\%) existing GenBank reference material. Unfortunately, the remaining 10, did not result in a close match and the exact species or genus of the host animals could not be determined for all virus hosts; except for 2, these sequences seemed to belong to different species. One animal could not be tested due to lack of material and 7 were not tested because the species had already been determined upon sample collection.

Fig. 3. Phylogenetic tree based on the Ter fragment amplified by the Chmielewicz PCR assay. Included are 50 previously published sequences and the 16 Ter sequences obtained. The published viruses included in the analyses are AciHV-2 (Acipenserid herpesvirus 2, EF535576), AlHV-1 (Alcelaphine herpesvirus 1, AF005370), AoHV-1 (Aotine herpesvirus 1, NC_016447), BHV-4 (Bovine herpesvirus 4, AF318573), CavHV-2 (Caviidherpesvirus 2, HG531783), CalHV-3 (Callitrichine herpesvirus 3, AF091067), CeHV-2 (Cercopithecine herpesvirus 2, AY714813), EHV-1 (Equid herpesvirus 1, AY665713), EHV-2 (Equid herpesvirus 2, NC_001650), EHV-4 (Equid herpesvirus 4, AF030027), EHV-5 (Equid herpesvirus 5, NC_026421), ElHV-1 (Elephant endotheliotropic herpesvirus 1, HM568515), ElHV-4 (Elephant endotheliotropic herpesvirus 4, NC_028379), FeHV-1 (Felid herpesvirus 1, KR381803), GaHV-1 (Gallid herpesvirus 1, NC_06623), GaHV-2 (Gallid herpesvirus 2, NC_002229), GaHV-3 (Gallid herpesvirus 3, AB049735), HHV-1 (Human herpesvirus 1, X14112), HHV-2 (Human herpesvirus 2, Z86099), HHV-4 (Human herpesvirus 4, AJ507799), HHV-5 (Human herpesvirus 5, AY446894), HHV-6 (Human herpesvirus 6, KY239023), HHV-7 (Human herpesvirus 7, NC_001716), HHV-8 (Human herpesvirus 8, NC_009333), McHV-1 (Macacine herpesvirus 1, AF533768), McHV-3 (Macacine herpesvirus 3, AY186194), MeHV-1 (Meleagrid herpesvirus 1, NC_002641), MuHV-1 (Murid herpesvirus 1, NC_004065), MuHV-2 (Murid herpesvirus 2, AF232689), MuHV-4 (Murid herpesvirus 4, NC_001826), MuHV-

\section{Discussion}

In this study we tested a large number of rodent and shrew specimens from CMR and the DRC for herpesvirus DNA and detected sequences indicative of various known and novel herpesviruses (Table 2). In the absence of full genomic sequences, knowledge about their biology, and serotype information, we assume the sequences probably indicate a novel distinct herpesvirus species if they differ by more than $10 \%$ from any known one. We based that assumption on the difference between the relatively closely related but distinct species HHV-1 and HHV-2. These 2 viruses differ by $9 \%$ in the region amplified by the Ter PCR and by $11 \%$ in the full gene sequence. In the case of the DPOL PCR the 2 viruses differ by $11 \%$ in the amplified part as well as in the gene overall. Each of these 2 genes, the DNA polymerase and the ATPase containing section of the terminase, are recommended by the ICTV for initial virus classification, since they are the only genes shared by all known members of the order Herpesvirales [3].

The proportion of samples containing herpesvirus DNA was $2.4 \%$, and thus lower than what was found in another study on a similar number of animals from Germany, the UK, and Thailand, which detected herpesvirus DNA in $27 \%$ of samples [11]. It is difficult to directly
7 (Murid herpesvirus 7, GQ169129), MuHV-8 (Murid herpesvirus 8, NC_019559), MusHV-1 (Mustelid herpesvirus 1, AF275656), PaHV-1 (Papiine herpesvirus 1, AF091052), PaHV-2 (Papiine herpesvirus 2, AF499022), PnHV-2 (Panine herpesvirus 2, AF480884), PsHV-1 (Psittacid herpesvirus 1, AY372243), RaHV-2 (Ranid herpesvirus 2, DQ665652), SgHV-1 (Callitrichine herpesvirus 1, AF091070), SuHV-1 (Suid herpesvirus 1, NC_006151), TuHV-1 (Tupaia herpesvirus 1, AF228035), AF193618 (Zalopus - California sea lion herpesvirus), EF151197 (Miniopterus schreibersii betaherpesvirus 1), JX294544 (Eptesicus isabellinus betaherpesvirus 1), JX294553 (Myotis mystacinus betaherpesvirus 1), JX294561 (Plecotus austriacus betaherpesvirus 1), JX294565 (Rousettus aegyptiacus betaherpesvirus 1), KR297253 (Mandrillus leucophaeus cytomegalovirus), KU578074 (Cercopithecus kandti cytomegalovirus), and U27238 (Stealth virus 1). The viral sequences isolated here are Rodent isolate MuHV-1, Shrew herpesvirus CMR 5 (KY398038), Shrew herpesvirus CMR 4 (KY398039), Shrew herpesvirus CMR 1 (KY398040) animals 15, 31, 65, and 99, Shrew herpesvirus CMR 2 (KY398041), Shrew herpesvirus CMR 3 (KY398042), Rodent herpesvirus DRC 1 (KY398043) animals 31, 81, and 89, Rodent herpesvirus CMR 1 (KY398044), Shrew herpesvirus DRC 1 (KY398045), Shrew herpesvirus DRC 2 (KY398046), and Shrew herpesvirus DRC 3 (KY765894). The tree is shown as a proportional cladogram; numbers at branches indicate posterior probabilities. 
compare the 2 studies due to differences in the setup and methodology, even though about $75 \%$ of our samples were tested with the same nested PCR for the amplification of a fragment of the DPOL gene $[11,14]$. The major distinguishing element, however, is the sample material, as we did not include neuronal tissues, lymph nodes, intestine or lung, but primarily blood ( $>60 \%$ of samples), liver, and spleen. Even among the sample types we included there was a clear difference, since we only detected 5 of the described sequences in blood samples. Looking at sample types separately, the prevalence would be $4.6 \%$ for tissue samples and $0.7 \%$ for blood samples, assuming that the different sampling and preparation methods had no major influence. One conclusion could be that we are thus missing the sites of latency for many of the known or suspected rodent herpesviruses, and are primarily seeing initial or reactivated infections. The choice of sampling material might also be the reason that we mainly detected sequences indicating betaherpesviruses (Table 2; Fig. 3).

The betaherpesvirus sequences we detected show an interesting clustering upon phylogenetic analysis. The 8 sequences obtained from shrews from different locations in CMR and the DRC (Fig. 2) cluster together in a separate branch with the next closest recognized genus being Muromegalovirus (Fig. 3). Taking the BLAST results into consideration, these sequences seem to clearly belong into the Betaherpesvirinae subfamily, yet this lineage might have separated from other betaherpesviruses some time ago, so that these could potentially be members of a unique Betaherpesvirinae genus (Fig. 3). More sequence data and knowledge about the biology of these viruses will be required to verify whether this is the case. Since 1 virus of this shrew cluster was also detected in a rodent (Shrew HV CMR 1), this does not seem to establish a species barrier (Table 2).

The limitations of the Cytochrome b PCR and sequencing to determine the species of sampled animals was not entirely unexpected, since for example only around half of all muroid rodents have Cytochrome $b$ DNA sequences available [16] and not all of these are available in GenBank. Through comparison of Cytochrome b data, however, we can conclude that our 24 virus-positive animals might belong to up to 19 different species.

Despite finding viral DNA in only 24 animals, we detected DNA indicative of 14 herpesviruses of potentially different species, which is a relatively high proportion. Taking into account that these were detected in up to 19 different species, host diversity likely contributed signifi- cantly to this outcome. In comparison, in the aforementioned study in Asia and Europe only about $10 \%$ of the detected herpesvirus sequences were unique, and in a similar study conducted on rodent and shrew rectal swabs in China, around $20 \%$ were unique herpesvirus sequences $[11,12]$.

This indicates that there is a high diversity of herpesviruses in wild African rodent and shrew species and the richness of rodent and shrew species in Africa is likely the reason for that $[17,18]$. Yet, it is conceivable that this is not just due to each host species having their own set of unique herpesviruses, but due to the availability of many different related host species. In this environment, herpesviruses likely have and have had more opportunity for interspecies transmission and a resulting increased diversification compared to environments with smaller species diversity. Further in-depth studies would be required to test this hypothesis. Overall the diverse herpesviruses of African rodents and shrews could pose an excellent opportunity to study herpesvirus evolution and host co-evolution, and might also provide opportunities for new models of human disease.

\section{Acknowledgements}

We thank the governments of Cameroon and the Democratic Republic of the Congo for permission to conduct this study. The authors thank the field teams and collaborating laboratories that performed sample collection and testing, especially the PREDICT/ DRC field staff in the Sankuru Province, as well as in the Health Zones of Kole, Lomela, and Tshudi-Loto. We also want to thank any other involved members of the PREDICT-1 consortium (http://www.vetmed.ucdavis.edu/ohi/predict/publications/Authorship.cfm). This study was made possible by the generous support of the American people through the United States Agency for International Development (USAID) Emerging Pandemic Threats PREDICT program (cooperative agreement No. GHN-A-OO09-00010-00). The contents are the responsibility of the authors and do not necessarily reflect the views of USAID or the United States Government.

\section{Statement of Ethics}

Specimen collection from wild animals was approved by the Institutional Animal Care and Use Committee (IACUC, UC Davis) and the governments of Cameroon and the Democratic Republic of the Congo.

\section{Disclosure Statement}

The authors declare no conflicts of interest. 


\section{References}

1 Davison AJ, Eberle R, Ehlers B, Hayward GS, McGeoch DJ, Minson AC, et al. The order Herpesvirales. Arch Virol. 2009;154(1):1717.

2 Davison AJ. Herpesvirus systematics. Vet Microbiol. 2010 Jun;143(1):52-69.

3 International Committee on Taxonomy of Viruses. Virus taxonomy: the classification and nomenclature of viruses. The 9 th report of the ICTV. 2011.

4 Pellet PE, Roizman B. Herpesviridae. In: Knipe DM, Howley PM, editors. Fields virology. 6th ed. Philadelphia: Wolters Kluver Health; 2013. p. 1802-22.

5 Escalera-Zamudio M, Rojas-Anaya E, Kolokotronis SO, Taboada B, Loza-Rubio E, Méndez-Ojeda ML, et al. Bats, Primates, and the Evolutionary Origins and Diversification of Mammalian Gammaherpesviruses. MBio. 2016 Nov;7(6):e01425-16.

6 Russell GC, Stewart JP, Haig DM. Malignant catarrhal fever: a review. Vet J. 2009 Mar; 179(3):324-35

7 Tischer BK, Osterrieder N. Herpesviruses - a zoonotic threat? Vet Microbiol. 2010 Jan; 140(3-4):266-70.
8 Farrell HE, Lawler C, Tan CS, MacDonald K, Bruce K, Mach M, et al. Murine Cytomegalovirus Exploits Olfaction To Enter New Hosts. MBio. 2016 Apr;7(2):e00251-16.

9 Alston CI, Dix RD. Murine cytomegalovirus infection of mouse macrophages stimulates early expression of suppressor of cytokine signaling (SOCS) 1 and SOCS3. PLoS One. 2017 Feb;12(2):e0171812.

10 Patel SJ, Zhao G, Penna VR, Park E, Lauron EJ, Harvey IB, et al. A Murine Herpesvirus Closely Related to Ubiquitous Human Herpesviruses Causes T-Cell Depletion. J Virol. 2017 Apr;91(9):e02463-16.

11 Ehlers B, Küchler J, Yasmum N, Dural G, Voigt S, Schmidt-Chanasit J, et al. Identification of novel rodent herpesviruses, including the first gammaherpesvirus of Mus musculus. J Virol. 2007 Aug;81(15):8091-100.

12 Zheng XY, Qiu M, Ke XM, Zhou W, Guan WJ, Chen SW, et al. Molecular Detection and Phylogenetic Characteristics of Herpesviruses in Rectal Swab Samples from Rodents and Shrews in Southern China. Vector Borne Zoonotic Dis. 2016 Jul;16(7):476-84.
13 Chmielewicz B, Goltz M, Ehlers B. Detection and multigenic characterization of a novel gammaherpesvirus in goats. Virus Res. 2001 May;75(1):87-94.

14 VanDevanter DR, Warrener P, Bennett L, Schultz ER, Coulter S, Garber RL, et al. Detection and analysis of diverse herpesviral species by consensus primer PCR. J Clin Microbiol. 1996 Jul;34(7):1666-71.

15 Townzen JS, Brower AV, Judd DD. Identification of mosquito bloodmeals using mitochondrial cytochrome oxidase subunit I and cytochrome b gene sequences. Med Vet Entomol. 2008 Dec;22(4):386-93.

16 Steppan SJ, Schenk JJ. Muroid rodent phylogenetics: 900-species tree reveals increasing diversification rates. PLoS One. 2017 Aug; 12(8):e0183070.

17 Monadjem A, Taylor PJ, Denys C, Cotterill FPD. Rodents of Sub-Saharan Africa. Berlin: De Gruyter; 2015.

18 Nicoll ME, Rathbun GB; IUCN/SSC Insectivore, Tree-Shrew, and Elephant-Shrew Specialist Group. African Insectivora and Elephant-shrews: An Action Plan for Their Conservation. Gland, Switzerland: ICUN; 1990. 